\title{
Review of Smart Hospital Services in Real Healthcare Environments
}

\author{
Hyuktae Kwon ${ }^{1, *}$, Sunhee $\mathrm{An}^{2, *}$, Ho-Young Lee ${ }^{3}$, Won Chul Cha ${ }^{4,5}$, Sungwan $\mathrm{Kim}^{2,6,7}$, Minwoo Cho ${ }^{8}$, \\ Hyoun-Joong Kong ${ }^{2,6,9}$ \\ ${ }^{1}$ Department of Family Medicine, Seoul National University Hospital, Seoul, Korea \\ ${ }^{2}$ Transdisciplinary Department of Medicine and Advanced Technology, Seoul National University Hospital, Seoul, Korea \\ ${ }^{3}$ Department of Nuclear Medicine, Seoul National University Bundang Hospital, Seongnam, Korea \\ ${ }^{4}$ Department of Emergency Medicine, Samsung Medical Center, Sungkyunkwan University School of Medicine, Seoul, Korea \\ ${ }^{5}$ Department of Digital Health, Samsung Advanced Institute for Health Science \& Technology (SAIHST), Sungkyunkwan University, Seoul, Korea \\ ${ }^{6}$ Institute of Medical \& Biological Engineering, Medical Research Center, Seoul National University College of Medicine, Seoul, Korea \\ ${ }^{7}$ Department of Biomedical Engineering, Seoul National University College of Medicine, Seoul, Korea \\ ${ }^{8}$ Biomedical Research Institute, Seoul National University Hospital, Seoul, Korea \\ ${ }^{9}$ Department of Medicine, Seoul National University College of Medicine, Seoul, Korea
}

Objectives: Smart hospitals involve the application of recent information and communications technology (ICT) innovations to medical services; however, the concept of a smart hospital has not been rigorously defined. In this study, we aimed to derive the definition and service types of smart hospitals and investigate cases of each type. Methods: A literature review was conducted regarding the background and technical characteristics of smart hospitals. On this basis, we conducted a focus group interview with experts in hospital information systems, and ultimately derived eight smart hospital service types. Results: Smart hospital services can be classified into the following types: services based on location recognition and tracking technology that measures and monitors the location information of an object based on short-range communication technology; high-speed communication network-based services based on new wireless communication technology; Internet of Things-based services that connect objects embedded with sensors and communication functions to the internet; mobile health services such as mobile phones, tablets, and wearables; artificial intelligence-based services for the diagnosis and prediction of diseases; robot services provided on behalf of humans in various medical fields; extended reality services that apply hyper-realistic immersive technology to medical practice; and telehealth using ICT. Conclusions: Smart hospitals can influence health and medical policies and create new medical value by defining and quantitatively measuring detailed indicators based on data collected from existing hospitals. Simultaneously, appropriate government incentives, consolidated interdisciplinary research, and active participation by industry are required to foster and facilitate smart hospitals.

Keywords: Hospital Design and Construction, Hospital Planning, Digital Technology, Meaningful Use, Health Services Administration

Submitted: July 5, 2021

Revised: 1st, November 25, 2021; 2nd, January 14, 2022

Accepted: January 15, 2022

\section{Corresponding Author}

Hyoun-Joong Kong

Transdisciplinary Department of Medicine and Advanced Technology, Seoul National University Hospital, 101 Daehak-ro, Jongno-gu, Seoul 03080, Korea. Tel: +82-2-2072-4492, E-mail: gongcop7@ snu.ac.kr (https://orcid.org/0000-0001-5456-4862)

*These authors contributed equally to this work.

This is an Open Access article distributed under the terms of the Creative Commons Attribution Non-Commercial License (http://creativecommons.org/licenses/by$\mathrm{nc} / 4.0 /$ ) which permits unrestricted non-commercial use, distribution, and reproduction in any medium, provided the original work is properly cited.

(c) 2022 The Korean Society of Medical Informatics

\section{Introduction}

In recent years, the focus in the medical field has shifted from disease treatment to prevention-oriented medicine, centering on medical consumers. In line with these changes, hospitals have introduced artificial intelligence (AI), robotics, and new technologies related to the Fourth Industrial Revolution, thereby raising expectations for improvements in the quality of disease diagnosis and treatment. There is an emerging need to reduce national medical costs by creating interconnections with other related medical facilities in the community, such as clinics, pharmacies, and rehabilitation 
centers, integrating the latest information and communication technologies (ICT); and providing "patient-centered care" services where patients are given access to various health information so that they can choose their own treatment methods $[1,2]$. For these reasons, various support measures to foster smart hospital-related industrial developments are being promoted in major countries, and the smart hospital-related market is expanding worldwide [1].

Efforts to apply ICT in the medical field have been made in the past, and this perspective was initially applied through the concept of the "digital hospital." The digital hospital is a concept that emerged in the early 2000s in Korea, with the goal of fostering a complete transformation from analog hospital workflows where charts, films, slips, papers, and pens were mostly used for all aspects of recording patients' medical histories to a digital hospital workflow involving the "four 'lesses"' (filmless, chartless, slipless, paperless) method by establishing computerized physician order-entry, picture archiving and communication systems, Electronic Medical Record (EMR) systems, and hospital business systems [3,4]. Nonetheless, although the word "smart" in "smart hospitals" has been analogized to the SMART (Specific, Measurable, Action-oriented, Realistic, and Time-bound) framework used rhetorically in the field of management, the concept has not been rigorously defined from an academic standpoint $[5,6]$.

Given the recent interest in smart hospitals, which are characterized by the application of recent innovative technology in the global information and communication field to medical services, this study sought to derive implications by exploring the definitions and service types of smart hospitals and reviewing cases of each type.

\section{Exploring the Concept of the Smart Hospital}

As a concept similar to smart hospitals, the term "intelligent hospitals" started to be used in the context of radiofrequency identification (RFID), in the Healthcare Consortium sponsored by the RFID Educational Foundation in the United States in 2009. With this concept, the researchers proposed a service that applies real-time location tracking technology, communication technology, and interoperability technology to various spaces in hospitals such as operating rooms, hospital wards, and outpatient clinics [7]. An organization called the Intelligent Health Association, with a focus on intelligent hospital product and service companies was established in the United States, and has been producing high-quality technology education, thereby promoting the adoption and implementation of new technology in the industry and expansion of the market. Medical institutions seek to improve patient management and safety, reduce medical costs, and revolutionize patient experiences through intelligent hospital services [8].

We conducted a literature review to define the concept of a smart hospital and derive its service types. The review was based on keywords such as "smart hospital," and we searched literature databases such as the Research Information Sharing Service (http://www.riss.kr), National Science \& Technology Information Service (http://www.ntis.go.kr), Google (http://scholar.google.co.kr, http://www.google.com), and others. Among the search results, papers, books, and trend reports that could provide an academic interpretation of the medical field were selected as the final research target. The literature introduced the concepts of smart hospitals in various ways, as shown in Table 1 [2,9-13].

McKinsey Health presented the main characteristics of smart hospitals [12] as the establishment of interoperability of systems, mobile integrated solutions, digitalization of all information, establishment of unified communication systems, provision of stable core infrastructure, and system automation. The Korea Health Industry Development Institute defined smart hospitals as a holistic system that requires the participation of all parties who provide medical consumeroriented services to improve their productivity and the accuracy of medical services by using ICT [1] (Table 2).

Following the literature review on smart hospitals, we conducted a focus group interview (FGI) to derive the concept of smart hospitals and the relevant service types. The FGI proceeded in the following order: selecting the interview subjects, sharing the literature review with the subjects, and an expert interview.

For the FGI, researchers who were faculty members in the department of hospital information system management and development at tertiary hospitals, as well as researchers with academic expertise in medical informatics or health information technology, were interviewed.

Upon providing the interviewees with the literature review results, we asked them to propose a smart hospital concept and the types of service it would provide. The discussion among the interviewees lasted until a consensus was reached. Smart hospitals can be defined as medical institutions that create new value and insights on patient safety, quality of care, cost-effectiveness, and patient-centeredness using ICT, and provide them in a quantitative manner to patients and medical staff. The services of smart hospitals can be categorized into eight types of technology: location recogni- 
Table 1. Various concepts of the "smart hospital"

\begin{tabular}{|c|c|}
\hline Category & Content \\
\hline Frost \& Sullivan [9] (2017) & $\begin{array}{l}\text { A medical institution that provides medical practices to minimize excessive expenditures } \\
\text { of users and prevent medical accidents in advance by using an integrated solution based } \\
\text { on information and communication. }\end{array}$ \\
\hline Karen Taylor [10] (2017) & $\begin{array}{l}\text { A medical institution that optimizes the ICT environment and establishes an automated } \\
\text { process with the aim of improving treatment procedures for existing patients and intro- } \\
\text { ducing new functions. }\end{array}$ \\
\hline $\begin{array}{l}\text { European Union Agency for } \\
\text { Network and Information } \\
\text { Security [11] (2016) }\end{array}$ & $\begin{array}{l}\text { A hospital that improves the patient treatment process based on IoT, optimizes asset man- } \\
\text { agement by establishing an ICT environment connected to the hospital's internal assets, } \\
\text { and utilizes a business automation process. }\end{array}$ \\
\hline $\begin{array}{l}\text { Korea Embedded Software and } \\
\text { System Industry Association } \\
{[12](2018)}\end{array}$ & $\begin{array}{l}\text { A medical institution that has built an integrated management system for safe patient care } \\
\text { and efficient hospital management by using ICT for various resources owned by the } \\
\text { hospital, such as medical personnel, facilities, information, and equipment. }\end{array}$ \\
\hline $\begin{array}{l}\text { Seoul Asan Hospital Innovation } \\
\text { Design Center [2] (2020) }\end{array}$ & $\begin{array}{l}\text { A next-generation hospital that exceeds the limits of existing hospitals in terms of quality } \\
\text { of care, patient safety, patient experience, and productivity by using technologies related } \\
\text { to the fourth industrial revolution. }\end{array}$ \\
\hline $\begin{array}{l}\text { Ministry of Health and Welfare } \\
\text { [13] (2020) }\end{array}$ & $\begin{array}{l}\text { A hospital that provides medical services by applying ICT such as } 5 \mathrm{G} \text { and IoT to improve } \\
\text { medical services such as enhancing patient safety, improving diagnosis and treatment } \\
\text { quality, and reducing costs. }\end{array}$ \\
\hline
\end{tabular}

ICT: information and communication technology, IoT: Internet of Things.

Table 2. Key features of smart hospitals introduced by McKinsey Health [12]

\begin{tabular}{|c|c|}
\hline Category & Content \\
\hline $\begin{array}{l}\text { A. Interoperability of } \\
\text { systems }\end{array}$ & $\begin{array}{l}\text { People, systems, and processes should be interconnected so that data can be efficiently shared } \\
\text { and integrated to assist with diagnosis, treatment, management, and business decision-making. }\end{array}$ \\
\hline $\begin{array}{l}\text { B. Mobile integrated } \\
\text { solutions }\end{array}$ & $\begin{array}{l}\text { All resources, such as people, equipment, and technology, are integrated into mobile to narrow } \\
\text { the point of treatment as much as possible. }\end{array}$ \\
\hline $\begin{array}{l}\text { C. Digitization of all } \\
\text { information }\end{array}$ & $\begin{array}{l}\text { All information generated in hospitals is stored in a separate and structured format for use in } \\
\text { report and analysis whenever possible, aiming for an automated, paperless workflow. }\end{array}$ \\
\hline $\begin{array}{l}\text { D. Establishment of a unified } \\
\text { communication system }\end{array}$ & $\begin{array}{l}\text { Through the integration of audio, video, and data, smooth and safe communication between all } \\
\text { stakeholders, including patients, caregivers, and medical staff, is made possible. }\end{array}$ \\
\hline $\begin{array}{l}\text { E. Provision of stable core } \\
\text { infrastructure }\end{array}$ & $\begin{array}{l}\text { Stable high-speed networking, perfect identification technology, and interconnection of sensor } \\
\text { networks and embedded systems. }\end{array}$ \\
\hline F. System automation & $\begin{array}{l}\text { A to E should be able to contribute to an improved patient treatment experience by increasing } \\
\text { the efficiency and productivity of hospital management. }\end{array}$ \\
\hline
\end{tabular}

tion and tracking technology, high-speed communication networks, the Internet of Things (IoT), mobile health, AI, robotics, extended reality, and telehealth.

\section{Examples of the Representative Service Types of Smart Hospitals}

\section{Location Recognition and Tracking Services}

Various services can be provided by measuring and moni- toring the location information of objects in a specific space using location recognition and tracking technology based on short-range communication technology [14]. The associated technologies include beacons, Bluetooth, Wi-Fi, Zigbee, RFID, GPS, A-GPS, barcodes, QR codes, and ultra-wideband communication (e.g., 5G technology standard). In particular, by introducing a tracking system for real-time assets (e.g., medical devices, medical supplies, and pharmaceutical products) based on beacon sensors and tags, medical institutions 
can improve the efficiency of logistics management related to hospital work and the workflow of medical staff $[15,16]$ (Figure 1).

The University Health System, a medical institution in the United States, introduced a smart infusion pump with an attached RFID, which has been reported to increase productivity and efficiency by reducing the time required for the medical staff to use the device in the hospital from the previous maximum of 2 hours to 8-12 minutes through real-time location monitoring [17].

\section{High-Speed Communication Network-based Services}

High-speed communication network-based services, such as $5 \mathrm{G}$ high-speed communication and Wi-Fi 6, provide medical services that overcome the previous limitations of data collection, utilization, and communication based on new wireless communication technology. Wi-Fi 6, as a highspeed communication network, is particularly suitable for use in hospital systems where there is a large volume of traffic and frequent environmental changes and updates. By using orthogonal frequency-division multiple access (OFDMA; Wi-Fi 6 technology that allows multiple clients with different requirements to access a single access point at the same time), the transmission waiting time can be reduced, and the target wake time function allows power-saving for devices and improved battery life. Using Wi-Fi 6, it is possible to accurately analyze patient records and real-time data and improve treatment outcomes by accurately administering medication following an objective decision-making process based on accurate, up-to-date patient data [18].

Wi-Fi 6-enabled medical devices, such as infusion pumps with adjustable data transfer times, can reduce usage overlap and improve the efficiency of device operation and maintenance through OFDMA by allowing up to 30 different devices to share the same infusion pump and channel without changing orders [19].

Researchers from Huazhong College of Science and Technology have proposed an integrated system termed "5GSmart Diabetes" that manages patients with diabetes using machine learning, medical big data, social networks, and smart clothing based on $5 \mathrm{G}$ wireless technology. Using $5 \mathrm{G}$ technology, this system continuously monitors physiological indicators in patients with diabetes, shares the relevant data, and applies a personalized data analysis model to provide tailored treatment services without any restrictions on the patient's daily life [20].

In addition, the reduction in data transmission time has upgraded the use of smart hospitals in terms of health monitoring. Through fast communication network services, health monitoring has become reliable anytime, anywhere. Even in emerging countries and hard-to-reach areas, a lack of data access is no longer a serious problem. To improve the situation further, research is being conducted on the use of a low peak-to-average power ratio, an efficient spectrum, low latency, and faster data compression and delivery [21].

\section{3. loT-based Services}

IoT-based services are technologies that connect various objects embedded with sensors and communication functions to the Internet, including object identification, network construction, sensor attachment (sensation), and action instruction (control) [22,23]. With IoT, smart hospitals can

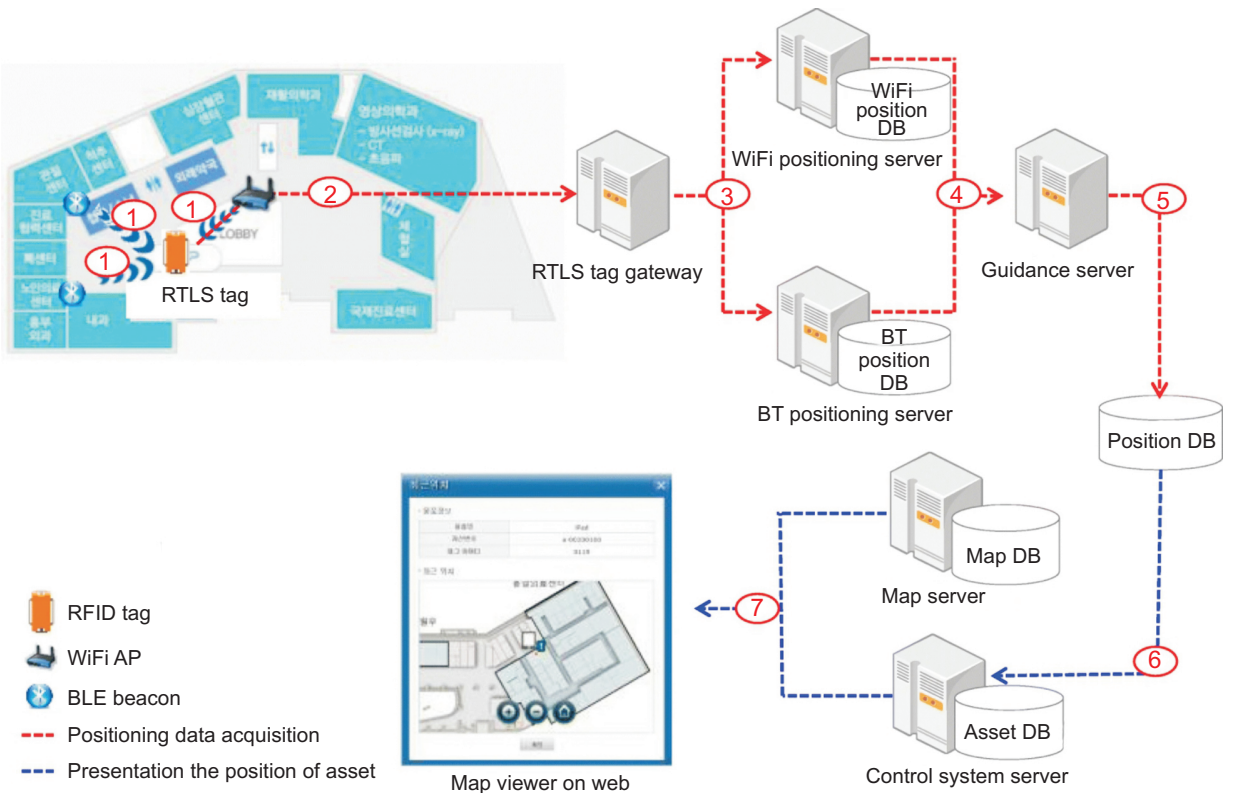

Map viewer on web
Figure 1. Example of an asset management service in hospitals. Adapted from Yoo et al. [15]. 
be developed by leveraging sensors, connection methods, internet protocols, databases, cloud computing, and analytics as infrastructure, and using multiple systems together in a composite [24]. IoT and intelligent building technologies can be used for a wide range of purposes, such as decreasing operating costs, increasing treatment effects, reducing diagnostic delays, detecting deterioration early, maximizing equipment utilization, improving patient safety, increasing energy efficiency in hospital buildings, increasing profitability, improving user experience, increasing operational efficiency, and protecting resources [25].

In the nursing field, IoT is used to automate the measurement of patients' vital signs and various indicators. IoTbased vital sign measurement sensors have been gradually miniaturized, as shown in Figure 2, to be attached or inserted into the body, and new indicators are being added, such as to measure patient posture and the number of steps [26]. Barcodes, RFID, fingerprint/iris/face recognition, and ultrasound-based recognition systems are used in smart hospital buildings [27].

The most actively used IoT-based technology is RFID systems, which are used for people, buildings, and medical devices, and research on the use of mobile near-field communication (NFC) systems has also been carried out [28-32].

A study at an academic medical center in the United States investigated the use of a system in which a patch is attached to patients in the intensive care unit that sends an alarm to nurses through the dashboard. It reported that this system reduced the incidence of bedsores in patients to approximately one-third of the original rate, thereby improving patient safety and cost efficiency [33]. An analysis of the effectiveness of a mobile EMR system based on short-range communication technology in hospital emergency rooms, as depicted in Figure 2, showed that it increased patient consul- tation time by optimizing the travel distance of the medical staff and reducing the time required for operating IT equipment $[31,33]$.

Recent research has also explored the use of machine learning and IoT to diagnose coronavirus disease 2019 (COVID-19) patients. The proposed model, which is based on machine learning and IoT, can serve as a clinical decision support system. In addition, the results are expected to contribute to reducing the excessive workload of doctors and solving the problem of patient overcrowding caused by COVID-19 [34].

\section{Mobile Health Services}

Mobile health services are services provided through mobile devices such as cell phones, tablets, and wearable devices. Personal health records (PHRs), as a mobile health record system, are built to allow self-monitoring and management by collecting treatment and examination information from various medical institutions, as well as activity level, weight, and blood glucose data collected by smartphones $[35,36]$. Previous PHR-related research addressed the usability of these systems and their ability to increase patient participation [37-39].

Researchers at the Icahn School of Medicine at Mount Sinai in the United States analyzed heart rate variability (HRV) data from medical staff asked to wear a smartwatch equipped with an app that measured HRV. The analysis revealed that COVID-19 infection could be detected through changes in HRV, even among those without symptoms. In an experiment performed at Stanford University, $81 \%$ of test participants wearing smart watches or fitness trackers were reported to have HRV up to 9 days before the onset of COVID-19 symptoms [40].

Given the fragmentation in the locations and subjects of


Figure 2. Examples of applications of Internet of Things technology in hospitals. (A) A mobile Electronic Medical Record (EMR) communicates with a near-field communication (NFC) system, and the mobile EMR displays progress after NFC tagging. (B) Combination of a wearable patient sensor and a dashboard. 
existing medical services, the demand for services such as mobile EMRs that medical staff use to contact patients in various places is also increasing. An NHS-based app in the United Kingdom provides access to hospital EMRs, prescription refills, appointments, and treatment plan reviews [41].

The use of mobile EMRs was confirmed to have partially increased actual work efficiency, but the results were often limited to Korea, and the research mostly focused on the targets and content [42] (Figure 3).

\section{Al-based Services}

AI-based services use intelligence (learning, reasoning, perception, and understanding abilities) as the main technological element for the diagnosis and prediction of diseases $[43,44]$. AI serves as the engine of clinical decision support systems, which help physicians make clinical decisions for diagnosis and prescription, thereby enhancing the effectiveness, efficiency, and safety of treatment. In particular, image data-based AI services are being developed rapidly.

Johns Hopkins Hospital in the United States maximized the efficiency of the hospital system by introducing GE's capacity command center (CCC) [45]. Furthermore, systems for making decisions using clinical data, not just by reading medical image data, are in progress [46].

Several hospitals have made efforts to introduce smart speakers. Many research results are expected to emerge owing to improvements in smart speakers' performance and increasing awareness among the public over the last 2 to 3 years. Patients can easily use the system, mainly for routine functions such as TV control, but the protection of personal information is a major issue $[47,48]$.

Several studies have reported on dashboard designs such as CCC, but reports on system improvements are rare. CCC was first applied in 2016, but only usability case reports have been published [49]. Although few studies have investigated the effects of AI dashboards, the effects of using data on system improvements have been demonstrated from various perspectives, and this framework has been applied to optimize human resource utilization, workflow improvement, and facilities [50].

\section{Robot Services}

Robot services involve robots performing medical actions on behalf of humans. The scope of these services in various fields includes surgery, rehabilitation, nursing care, and logistics.

As a remote collaborative care robot, "Rudy" by INF Robotics has nursing and telemedicine capabilities [43]. Seoul National University Hospital developed a robotic system using telepresence technology, which promotes direct commu-



Figure 3. Examples of hospital mobile terminal-based services. (A) Seoul National University Hospital's PHR service. Using the application, the patient can check information such as the treatment schedule, treatment details, results of test, and prescription drugs. (B) Samsung Seoul Hospital's mobile EMR service (DARWIN). PHR: personal health record, EMR: Electronic Medical Record. 
nication between patients and medical staff to enable remote collaborative care. An economic evaluation showed that people made 4.01 times fewer doctor visits per year since the robot was deployed $[51,52]$.

The Baylor Scott and White Health Care System evaluated the effect of the pet robot PARO, an FDA-approved biofeedback device, on the treatment of symptoms related to dementia and found that PARO reduced the pulse rate and the use of analgesics and psychoactive drugs [53]. Boston Children's Hospital reported that a conversational social robot provided to children aged 3-10 years had a positive emotional impact [54].

Other caring service robots [43] include the excretion support robot by Cyberdyne, a rehabilitation robot company; TUG, an autonomous transport robot developed by Aethon in the United States that transfers and transports blood, medicines, meals, and garbage [55]; Cuboid, developed by Wireless City Planning; HOSPI, developed by Panasonic; quarantine robots such as GermFalcon, an aircraft sterilization robot sold by Dimer UVC Innovations; and UVD, produced by UVD Robots, a Danish robot company [56]. Examples of the use of medical services provided by robots are shown in Figure 4.

\section{Extended Reality Services}

Extended reality refers to ultra-realistic technologies and services, including virtual reality (VR), augmented reality $(A R)$, and mixed reality (MR). VR enables a virtual experience by providing a virtual signal to the user's senses, whereas $\mathrm{AR}$ augments reality by providing digital information. MR combines AR with VR in the real world [57].

VR in healthcare applications can potentially be used for clinical skills, training, and education of practitioners to address cognitive, psychological, motor, and functional im- pairments. Clinicians are showing more interest in clinical trials and applied research with VR simulations because of the encouraging comments published in the medical literature [58]. Furthermore, certain surgical skills acquired via a VR simulator can be transferred to the operating room, and actual surgical performance can be predicted from its results [59].

The Imperial College Healthcare NHS Trust developed AR technology for extremity reconstruction surgery using a three-dimensional (3D) vascular model with perforating vessels. This system enables the preoperative identification of anatomical structures without an incision by providing CT angiography information. It reduces anesthesia time and adverse outcomes related to surgery, shortens surgical training time, and provides remote support for surgery. In addition, through drug information provision technology using $\mathrm{AR}$, patients can see the mechanism of action of drugs in a $3 \mathrm{D}$ graphic format $[60,61]$.

Virtual Iraq is a program that is part of BraveMind and was developed by the US Department of Defense and the University of Southern California [62]. They created a VR program based on clinical data to treat soldiers with PTSD [63]. VIPAAR (http://helplightning.com) has been providing telemedicine technology using MR in North America. In addition, the Surgical Navigation Advanced Platform (https:// www.surgicaltheater.com/) is an AR/VR solution that helps doctors establish precise and stable surgical plans by identifying the three-dimensional structures of blood vessels and nerves in the brain during head and neck surgery.

Shionogi Pharmaceutical in Japan developed a digital therapeutic app, AKL-T01, which led to significant improvements in children with attention deficit hyperactivity disorder who regularly played games with individually optimized difficulty levels using the app [64]. A clinical trial of reSET, a


Figure 4. Examples of the use of medical services by robots. (A) Autonomous transport robot, TUG. Adapted from Siao et al. [55]. (B) Quarantine robot, UVD. Adapted from Holland et al. [56]. (C) Remote collaborative care robot at Seoul National University Hospital. Adapted from Lee and Kim [52]. 
Table 3. Telehealth-related research trends

\begin{tabular}{|c|c|c|c|c|c|}
\hline Study & Hospital & ICU mortality change & $\begin{array}{l}\text { Average LOS } \\
\text { change }\end{array}$ & $\begin{array}{l}\text { Study type } \\
\text { (design) }\end{array}$ & Outcome variable \\
\hline $\begin{array}{l}\text { Rosenfeld } \\
\text { et al. [68] } \\
(2000)\end{array}$ & $\begin{array}{l}\text { A 10-bed surgical ICU } \\
\text { in at Johns Hopkins } \\
\text { Medical Institution }\end{array}$ & $\begin{array}{l}\text { Severity-adjusted } \\
\text { mortality rate in the } \\
\text { ICU decreased by } \\
46 \% \text { - Hospital by } \\
30 \%\end{array}$ & $\begin{array}{l}\text { ICU length } \\
\text { of stay de- } \\
\text { creased by } \\
30 \%\end{array}$ & $\begin{array}{l}\text { Observational } \\
\text { time series } \\
\text { triple cohort } \\
\text { study }\end{array}$ & $\begin{array}{l}\text { Surgical ICU in a 450-bed, } \\
\text { academic-affiliated hospital }\end{array}$ \\
\hline $\begin{array}{l}\text { Zawada et al. } \\
\text { [69] (2009) }\end{array}$ & $\begin{array}{l}\text { Conducted in Avera } \\
\text { Health System (one } \\
\text { large tertiary hospital, } \\
\text { three rural hospitals, } \\
\text { two community hos- } \\
\text { pitals and } 9 \text { critical } \\
\text { care centers) }\end{array}$ & $\begin{array}{l}\text { Adjusted mortality } \\
\text { rate ranged between } \\
\text { unchanged and 29\% } \\
\text { reduction }\end{array}$ & $\begin{array}{l}\text { LOS reduction } \\
\text { ranged from } \\
22.5 \% \text { to } 45 \% \\
\text { (9 sites) }\end{array}$ & $\begin{array}{l}\text { Observational } \\
\text { time series } \\
\text { cohort study }\end{array}$ & $\begin{array}{l}\text { 506-bed tertiary referral } \\
\text { hospital for the Avera Health } \\
\text { System, } 3 \text { rural regional hos- } \\
\text { pitals with 10, 6, and } 10 \text { ICU } \\
\text { beds, respectively, } 2 \text { com- } \\
\text { munity hospitals ( } 100 \text { total } \\
\text { beds), and } 9 \text { critical access } \\
\text { hospitals ( } 25 \text { beds) }\end{array}$ \\
\hline $\begin{array}{l}\text { Morrison } \\
\text { et al. [70] } \\
(2010)\end{array}$ & $\begin{array}{l}\text { Two community hospi- } \\
\text { tals in the metropoli- } \\
\text { tan Chicago area }\end{array}$ & $\begin{array}{l}\text { No significant effect } \\
\text { on ICU or non-ICU/ } \\
\text { total mortality }\end{array}$ & $\begin{array}{l}\text { No effect on } \\
\text { LOS }\end{array}$ & $\begin{array}{l}\text { Before-and- } \\
\text { after trial }\end{array}$ & $\begin{array}{l}\text { Two adult ICUs in a } 650 \text {-bed } \\
\text { tertiary care teaching hospi- } \\
\text { tal }\end{array}$ \\
\hline $\begin{array}{l}\text { Lilly et al. } \\
\text { [71] (2011) }\end{array}$ & $\begin{array}{l}\text { University of } \\
\text { Massachusetts }\end{array}$ & $2.1 \%$ decrease & $\begin{array}{l}1.9 \text { days } \\
\text { decrease }\end{array}$ & $\begin{array}{l}\text { Prospective } \\
\text { stepped- } \\
\text { wedge clinical } \\
\text { practice study }\end{array}$ & $\begin{array}{l}7 \text { ICUs ( } 3 \text { medical, } 3 \text { surgical, } \\
\text { and } 1 \text { mixed cardiovascular) } \\
\text { on } 2 \text { campuses of an } 834 \text {-bed } \\
\text { academic medical center }\end{array}$ \\
\hline $\begin{array}{l}\text { Young et al. } \\
\text { [72] (2011) }\end{array}$ & Review & $\begin{array}{l}\text { Odds ratio for } \\
\text { pooled data was } \\
0.80 \text {, showing a } \\
\text { reduction }\end{array}$ & $\begin{array}{l}1.26 \text { days de- } \\
\text { crease }\end{array}$ & & \\
\hline
\end{tabular}

ICU: intensive care unit, LOS: length of stay.

drug addiction treatment app developed by Pear Therapeutics, showed that the proportion of patients who remained abstinent while using the app was $40.3 \%$, which was higher than that of patients who did not use the app (17.6\%) [65].

\section{Telehealth}

Telehealth refers to a form of medical services provided from a distant site using ICT and includes concepts such as a tele-intensive care unit (tele-ICU), tele-consulting, and telecollaboration. Telehealth can be performed synchronously (telephone and video), asynchronously (patient portal messages, e-consults), and through virtual agents (chatbots) and wearable devices, without physical contact [66].

In the United States, American Well and Doctor on Demand provide primary care to people living in remote locations. Twine Health, acquired by Fitbit, allows patients to work with doctors to create action plans and use the device and apps to track progress and induce behavioral changes. Through tablets, patients have discussions with their health coaches and participate in the treatment process. TytoCare is a portable device that allows parents to consult with clinicians by sharing images and records through video chats to monitor their children's diseases and analyze the results.

A tele-ICU [67] is connected through an external command center to patients and medical staff via real-time audio-visual and electronic means in the ICU to exchange medical information [68-72]. According to a study by Rosenfeld et al. [68] at Johns Hopkins Hospital, an analysis of the financial impacts of the tele-ICU program showed that the length of stay in the ICU was shortened and the clinical results were improved, resulting in a $24.6 \%$ reduction in cost per case (Table 3).

\section{Discussion}

From the viewpoint of patient safety, quality of care, costeffectiveness, and patient-centered services, we have shown through practical examples that smart hospital services can 
create new value and insights that are not provided by existing medical services and provide them to patients and medical staff.

The eight services provided by smart hospitals are expected to contribute to solving the following issues in medical institutions related to the COVID-19 response. By applying location recognition and tracking, IoT, and AI technologies to asset management and patient monitoring in the ward, it will be possible to improve the efficiency of integrated nursing care services. Using robots, high-speed communication, $\mathrm{XR}$, and telehealth technologies for patient-to-doctor telemedicine and professional-to-professional telementoring, treatment, education, and training in medical institutions will be operated more safely and efficiently.

The following policy efforts are needed to motivate useful smart-hospital services within medical institutions. First, the government should encourage the spread of smart hospitals through various policies. The market size should be expanded through various policies to revitalize the smart-hospitalrelated industrial ecosystem. Appropriate incentive policies to motivate existing hospitals to transform into smart hospitals are needed. It is necessary to promote the spread of smart hospitals through direct and indirect incentives such as medical institution certification and related fee settings.

Second, it is necessary for medical institutions to revise and supplement the existing hospital work process so that the technological units of smart hospital services can be actively reflected in the design of new building spaces, as well as in spaces and facilities in existing hospitals.

With the introduction of smart hospitals, preventive health management is provided in various living spaces of local communities, such as homes and workplaces, using the latest ICTs, such as mobile and wearable sensors, which is expected achieve customer-centered medical services that can be accessed from the comfort of people's residences through the virtual expansion of hospitals without physical space restrictions. In addition, based on the data collected through smart hospitals, specific detailed indicators related to the core aspects of medical value can be defined, quantitatively measured, and fed back to inform healthcare policy.

Third, industry needs to maintain a close cooperative relationship with medical institutions, which are the consumers of the services, and pursue the commercialization of related technologies based on demonstrations in the practical medical field.

Finally, stakeholders from industry, academia, research, and the medical field should form a standardization-related consultative body to maintain close communication, lead standardization in domestic and foreign industries, and contribute to improving competitiveness in the relevant market [73].

Data collected through smart hospital services within medical institutions will contribute to the establishment of national healthcare policies by defining and quantitatively measuring detailed indicators related to core aspects of medical value. The active introduction of the smart hospital concept will enable preventive health management in the various living spaces of local communities, such as homes and work, beyond the physical space constraints of existing hospitals. This "virtual expansion of hospitals" will contribute to the realization of customer-oriented medical services that individuals encounter in their daily lives.

\section{Conflict of Interest}

Hyoun-Joong Kong is an editorial member of Healthcare Informatics Research; however, he did not involve in the peer reviewer selection, evaluation, and decision process of this article. Otherwise, no potential conflict of interest relevant to this article was reported.

\section{Acknowledgments}

This research is partly based on the KOSMI Issue Report (2020), which was supported by the Ministry of Health and Welfare, Republic of Korea. And this research was supported by the Ministry of Science and ICT, Korea, under the Information Technology Research Center support program (No. IITP-2020-2021-0-01833) supervised by the Institute for Information \& communications Technology Promotion (IITP).

\section{ORCID}

Hyuktae Kwon (https://orcid.org/0000-0002-0312-3650)

Sunhee An (https://orcid.org/0000-0001-9424-0977)

Ho-Young Lee (https://orcid.org/0000-0001-6518-0602)

Won Chul Cha (https://orcid.org/0000-0002-2778-2992)

Sungwan Kim (https://orcid.org/0000-0002-9318-849X)

Minwoo Cho (https://orcid.org/0000-0003-2242-4747)

Hyoun-Joong Kong (https://orcid.org/0000-0001-5456-4862)

\section{References}

1. Korea Health Industry Statistics. Analysis of the background and characteristics of smart hospitals. Global Health Ind Trends 2019;325:1-4. 
2. Seoul Asan Hospital Innovation Design Center. We make human-centered hospitals. Seoul, Korea: CloudNine Publisher; 2020.

3. Korea Digital Hospital Export Agency. Overview of digital hospitals [Internet]. Seoul, Korea: Korea Digital Hospital Export Agency; c2012 [cited at 2022 Feb 3]. Available from: http://kor.kohea.co.kr/hospital_overview/.

4. Cho NW. Sung Sang-cheol, President of Seoul National University Bundang Hospital, which is about to open next June [Internet]. Seoul, Korea: Financial News; 2002 [cited at $2022 \mathrm{Feb} 3$ ]. Available from: http://news.naver. $\mathrm{com} / \mathrm{main} / \mathrm{read} . \mathrm{nhn}$ ? mode $=\mathrm{LPOD} \& \mathrm{mid}=\mathrm{etc} \&$ oid $=014$ \&aid $=0000026478$.

5. Indeed Editorial Team. SMART goals: definition and examples [Internet]. Austin (TX): Indeed; c2022 [cited at $2022 \mathrm{Feb} 3]$. Available from: https://www.indeed.com/ career-advice/career-development/smart-goals.

6. Wikipedia. SMART [Internet]. [place unknown]: Wikipedia; 2022 [cited at $2022 \mathrm{Feb} 3$ ]. Available from: https:// en.wikipedia.org/wiki/SMART_criteria.

7. Frisch P. What is an intelligent hospital?: a place where technology and design converge to enhance patient care. IEEE Pulse 2014;5(6):10-5.

8. Intelligent Health Association. Welcome to your association [Internet]. Media (PA): Intelligent Health Association; 2020 [cited at 2022 Feb 3]. Available from: http:// ihassociation.org.

9. Frost \& Sullivan. Smart hospitals to invest over $€ 9.61$ billion in cloud computing and data analytics, says Frost \& Sullivan [Internet]. San Antonio (TX): Frost \& Sullivan; 2017 [cited at $2022 \mathrm{Feb} 3$ ]. Available from: https:// www.frost.com/news/press-releases/smart-hospitalsinvest-over-11-billion-cloud-computing-and-dataanalytics-says-frost-sullivan/.

10. Taylor K. Smart hospitals: how technology is redefining future healthcare [Internet]. London, UK: Deloitte UK Centre for Health Solutions; 2017 [cited at 2022 Feb 3]. Available from: https://blogs.deloitte.co.uk/ health/2017/06/smart-hospitals-how-technology-isredefining-future-healthcare.html.

11. European Union Agency for Network and Information Security. Smart hospitals: security and resilience for smart health service and infrastructures [Internet]. Heraklion, Greece: European Union Agency for Network and Information Security; 2016 [cited at 2022 Feb 3]. Available from: https://www.enisa.europa.eu/publications/cyber-security-and-resilience-for-smart-hospitals/
at_download/fullReport.

12. Yoon YD. Smart hospital-related technology status and prospects. KESSIA Issue Rep 2018;(2):1-9.

13. Ministry of Culture, Sports and Tourism. The smart hospital, opening a foundation for medical service innovation in the era of the 4 th industrial revolution [Internet]. Sejong, Korea: Ministry of Culture, Sports and Tourism; 2020 [cited at 2022 Feb 3]. Available from: https://www.korea.kr/news/pressReleaseView. do?newsId $=156408065$.

14. INNOPOLIS Foundation. Real-time location tracking systems market [Internet]. Daejeon, Korea: INNOPOLIS Foundation; 2018 [cited at 2020 Feb 3]. Available from: https://www.innopolis.or.kr/board/view?linkId=4 4007\&menuId=MENU00999.

15. Yoo S, Kim S, Kim E, Jung E, Lee KH, Hwang H. Realtime location system-based asset tracking in the healthcare field: lessons learned from a feasibility study. BMC Med Inform Decis Mak 2018;18(1):80.

16. Yamashita K, Oyama S, Otani T, Yamashita S, Furukawa T, Kobayashi D, et al. Smart hospital infrastructure: geomagnetic in-hospital medical worker tracking. J Am Med Inform Assoc 2021;28(3):477-86.

17. Zebra. University Health System: Passive smart pump management is more productive, reliable and costeffective [Internet]. Lincolnshire (IL): Zebra Technologies Corporation; [cited at 2022 Feb 3]. Available from: https://hpaust.com/wp-content/uploads/2020/09/ Success-Story-University-Health-System.pdf.

18. Islam A. Benefits of Wi-Fi 6 for healthcare providers [Internet]. Crawley, UK: Spirent Communications; 2020 [cited at $2022 \mathrm{Feb} 3$ ]. Available from: https://www.spirent.kr/blogs/benefits-of-wi-fi-6-for-healthcare-providers.

19. White J. Wi-Fi 6 and healthcare [Internet]. Austin (TX): Wi-Fi Alliance; 2019 [cited at 2022 Feb 3]. Available from: http://www.wi-fi.org/beacon/jay-white/wi-fi6-and-healthcare.

20. Chen M, Yang J, Zhou J, Hao Y, Zhang J, Youn CH. 5Gsmart diabetes: toward personalized diabetes diagnosis with healthcare big data clouds. IEEE Commun Mag 2018;56(4):16-23.

21. Kumar A, Bhargav A, Karthikeyan A, Rajagopal K, Srinivasan AK, Tsegay AN. Low computational artificial intelligence genetic algorithm assisted SLM PAPR reduction technique for upcoming $5 \mathrm{G}$ based smart hospital. In: Malik H, Iqbal A, Joshi P, Agrawal S, Bakhsh FI, editors. Metaheuristic and evolutionary computation: 
algorithms and applications. Singapore: Springer; 2021. p. 555-67.

22. Oracle. What is IoT? [Internet]. Austin (TX): Oracle; c2022 [cited at 2022 Feb 3]. Available from: https:// www.oracle.com/internet-of-things/what-is-iot/.

23. Wikipedia. Internet of Things [Internet]. [place unknown]: Wikipedia; c2021 [cited at $2022 \mathrm{Feb} 3$ ]. Available from: https://ko.wikipedia.org/wiki/\%EC\%82\%A C\%EB\%AC\%BC\%EC\%9D\%B8\%ED\%84\%B0\%EB\%84 $\% \mathrm{~B} 7$.

24. Uslu BC, Okay E, Dursun E. Analysis of factors affecting IoT-based smart hospital design. J Cloud Comput (Heidelb) 2020;9(1):67.

25. Korea Health Industry Development Institute. A study on smart hospital developing plans for medical service innovation in the digital era. Osong, Korea: Korea Health Industry Development Institute; 2020.

26. Darshan KR, Anandakumar KR. A comprehensive review on usage of Internet of Things (IoT) in healthcare system. Proceedings of 2015 International Conference on Emerging Research in Electronics, Computer Science and Technology (ICERECT); 2015 Dec 17-19; Mandya, India.

27. Omar O. Intelligent building, definitions, factors and evaluation criteria of selection. Alex Eng J 2018;57(4):2903-10.

28. Wu B, Liu Z, George R, Shujaee KA. eWellness: building a smart hospital by leveraging RFID networks. Proceedings of the 27th Annual International Conference of the IEEE Engineering in Medicine and Biology Society; 20156 Jan 17-18; Shanghai, China.

29. Guinard PF. Building a smart hospital using RFID technologies. Proceedings of European Conference on eHealth; 2006 Oct 12-13; Fribourg, Switzerland.

30. Park JH, Seol JA, Oh YH, Design and implementation of an effective mobile healthcare system using mobile and RFID technology. Proceedings of 7th International Workshop on Enterprise Networking and Computing in Healthcare Industry; 2005 Jun 23-25; Busan, Korea.

31. Jung KY, Kim T, Jung J, Lee J, Choi JS, Mira K, et al. The effectiveness of near-field communication integrated with a mobile electronic medical record system: emergency department simulation study. JMIR Mhealth Uhealth 2018;6(9):e11187.

32. Essink HM, Knops A, Liqui Lung AM, van der Meulen CN, Wouters NL, van der Molen AJ, et al. Real-time person identification in a hospital setting: a systematic review. Sensors (Basel) 2020;20(14):3937.
33. Pickham D, Berte N, Pihulic M, Valdez A, Mayer B, Desai M. Effect of a wearable patient sensor on care delivery for preventing pressure injuries in acutely ill adults: a pragmatic randomized clinical trial (LS-HAPI study). Int J Nurs Stud 2018;80:12-9.

34. Abdulkareem KH, Mohammed MA, Salim A, Arif M, Geman O, Gupta D, et al. Realizing an effective COVID-19 diagnosis system based on machine learning and IOT in smart hospital environment. IEEE IoTJ 2021;8(21):15919-28.

35. Burrington-Brown J, Fishel J, Fox L, Friedman B, Giannangelo K, Jacobs E, et al. Defining the personal health record: AHIMA releases definition, attributes of consumer health record. J AHIMA 2005;76(6):24-5.

36. Lee K. Personal health record (PHR) [Internet]. Newton (MA): SearchHealthIT; 2017 [cited at $2022 \mathrm{Feb} 3$ ]. Available from: https://searchhealthit.techtarget.com/ definition/personal-health-record-PHR.

37. Kim SM, Kim T, Cha WC, Lee JH, Kwon IH, Choi Y, et al. User experience of mobile personal health records for the emergency department: mixed methods study. JMIR Mhealth Uhealth 2020;8(12):e24326.

38. Dameff C, Clay B, Longhurst CA. Personal health records: more promising in the smartphone era? JAMA 2019;321(4):339-40.

39. Niazkhani Z, Toni E, Cheshmekaboodi M, Georgiou A, Pirnejad H. Barriers to patient, provider, and caregiver adoption and use of electronic personal health records in chronic care: a systematic review. BMC Med Inform Decis Mak 2020;20(1):153.

40. Lee JH. Smartwatch detects "COVID-19 early detected 7 days before symptoms" [Internet]. Seoul, Korea: GDnet Korea; 2021 [cited at $2022 \mathrm{Feb} 3$ ]. Available from: https://zdnet.co.kr/view/?no=20210119105410.

41. NHS. About the NHS App [Internet]. Bethesda (MD): NHS; 2021 [cited at 2022 Feb 3]. Available from: https:// www.nhs.uk/nhs-services/online-services/nhs-app/ about-the-nhs-app.

42. Kim S, Ku S, Kim T, Cha WC, Jung KY. Effective use of mobile electronic medical records by medical interns in real clinical settings: mixed methods study. JMIR Mhealth Uhealth 2020;8(12):e23622.

43. IssueQuest. Development status and market prospects for medical and healthcare artificial intelligence (AI) and service robot technology. Seoul, Korea: IssueQuest; 2020.

44. Korea Intellectual Property Strategy Agency Future Technology Team. Patent megatrend analysis report (bi- 
ology). Seoul, Korea: Korea Intellectual Property Strategy Agency; 2019.

45. Johns Hopkins Medicine. The Johns Hopkins Hospital launches capacity command center to enhance hospital operations [Internet]. Baltimore (MD): The Johns Hopkins Medicine; 2016 [cited at 2022 Feb 3]. Available from: http://www.hopkinsmedicine.org/news/media/releases/the_johns_hopkins_hospital_launches_capacity_ command_center_to_enhance_hospital_operations.

46. VUNO. Our history [Internet]. Seoul, Korea: VUNO Inc.; c2021 [cited at $2022 \mathrm{Feb} 3$ ]. Available from: https:// www.vuno.co/.

47. Gurak R. Can smart speakers improve the patient experience at hospitals? [Internet]. [place unknown]: The Dice Group; 2020 [cited at 2022 Feb 3]. Available from: http://medium.com/dice-group/can-smartspeakers-improve-the-patient-experience-at-hospitals69241 a849937.

48. Cedars-Sinai. Cedars-Sinai Taps Alexa for smart hospital room pilot [Internet]. Los Angeles (CA): CedarsSinai; 2019 [cited at $2022 \mathrm{Feb} 3$ ]. Available from: http:// www.cedars-sinai.org/newsroom/cedars-sinai-tapsalexa-for-smart-hospital-room-pilot.

49. Martinez DA, Kane EM, Jalalpour M, Scheulen J, Rupani $\mathrm{H}$, Toteja $\mathrm{R}$, et al. An electronic dashboard to monitor patient flow at the Johns Hopkins Hospital: communication of key performance indicators using the Donabedian model. J Med Syst 2018;42(8):133.

50. Kasten JE. Big data applications in healthcare administration. Int J Big Data Anal Healthc 2020;5(2):12-37.

51. Jang SM, Lee K, Hong YJ, Kim J, Kim S. Economic evaluation of robot-based telemedicine consultation services. Telemed J E Health 2020;26(9):1134-40.

52. Lee HS, Kim J. Scenario-based assessment of user needs for point-of-care robots. Healthc Inform Res 2018;24(1): 12-21.

53. Petersen S, Houston S, Qin H, Tague C, Studley J. The utilization of robotic pets in dementia care. J Alzheimers Dis 2017;55(2):569-74.

54. Logan DE, Breazeal C, Goodwin MS, Jeong S, O'Connell B, Smith-Freedman D, et al. Social robots for hospitalized children. Pediatrics 2019;144(1):e20181511.

55. Siao CY, Chien TH, Chang RG. Robot scheduling for assistance and guidance in hospitals. Appl Sci 2022;12(1):337.

56. Holland J, Kingston L, McCarthy C, Armstrong E, O’Dwyer P, Merz F, et al. Service robots in the healthcare sector. Robotics 2021;10(1):47.

57. Kim SB. Health industry 4 th industrial revolution series: medical augmented reality (AR)/virtual reality (VR) market trend analysis. KHIDI Brief 2017;251:1-15.

58. Aziz HA. Virtual reality programs applications in healthcare. J Health Med Inform 2018;9(1):305.

59. Schmidt MW, Koppinger KF, Fan C, Kowalewski KF, Schmidt LP, Vey J, et al. Virtual reality simulation in robot-assisted surgery: meta-analysis of skill transfer and predictability of skill. BJS Open 2021;5(2):zraa066.

60. Pratt P, Ives M, Lawton G, Simmons J, Radev N, Spyropoulou L, et al. Through the HoloLens ${ }^{\text {mox }}$ looking glass: augmented reality for extremity reconstruction surgery using 3D vascular models with perforating vessels. Eur Radiol Exp 2018;2(1):2.

61. The Medical Futurist. Augmented reality in healthcare: 9 examples [Internet]. Budapest, Hungary: The Medical Futurist; 2021 [cited at 2022 Feb 3]. Available from: http://medicalfuturist.com/augmented-reality-inhealthcare-will-be-revolutionary/.

62. Treskunov A. Virtual Iraq for post traumatic stress disorder treatment [Internet]. [place: publisher unknown]; 2010 [cited at $2022 \mathrm{Feb} 3$ ]. Available from: http://anton. treskunov.net/projects/ptsd.

63. Mozgai S, Hartholt A, Rizzo A. Iterative participatory design for VRET domain transfer: from combat exposure to military sexual trauma. Proceedings of Extended Abstracts of the 2020 CHI Conference on Human Factors in Computing Systems; 2020 Apr 25-30; Honolulu, HI.

64. Choi SR. Shionogi's ADHD treatment app received approval from the US FDA [Internet]. Seoul, Korea: Yakup.com; 2020 [cited at 2022 Feb 3]. Available from: http://m.yakup.com/?m=n\&mode=view\&nid=245990.

65. Yoo JH. Games, apps, and VR instead of drugs... The world of 'digital therapy' opens up [Internet]. Seoul, Korea: chosun.com; 2020 [cited at 2022 Feb 3]. Available from: http://www.chosun.com/site/data/html_ dir/2020/06/21/2020062102171.html.

66. Wosik J, Fudim M, Cameron B, Gellad ZF, Cho A, Phinney $\mathrm{D}$, et al. Telehealth transformation: COVID-19 and the rise of virtual care. J Am Med Inform Assoc 2020; 27(6):957-62.

67. Kumar S, Merchant S, Reynolds R. Tele-ICU: efficacy and cost-effectiveness approach of remotely managing the critical care. Open Med Inform J 2013;7:24-9.

68. Rosenfeld BA, Dorman T, Breslow MJ, Pronovost P, Jenckes $\mathrm{M}$, Zhang $\mathrm{N}$, et al. Intensive care unit telemedicine: alternate paradigm for providing continuous intensivist care. Crit Care Med 2000;28(12):3925-31. 
69. Zawada ET Jr, Herr P, Larson D, Fromm R, Kapaska D, Erickson D. Impact of an intensive care unit telemedicine program on a rural health care system. Postgrad Med 2009;121(3):160-70.

70. Morrison JL, Cai Q, Davis N, Yan Y, Berbaum ML, Ries $\mathrm{M}$, et al. Clinical and economic outcomes of the electronic intensive care unit: results from two community hospitals. Crit Care Med 2010;38(1):2-8.

71. Lilly CM, Cody S, Zhao H, Landry K, Baker SP, McIlwaine J, et al. Hospital mortality, length of stay, and preventable complications among critically ill patients before and after tele-ICU reengineering of critical care processes. JAMA 2011;305(21):2175-83.

72. Young LB, Chan PS, Lu X, Nallamothu BK, Sasson C, Cram PM. Impact of telemedicine intensive care unit coverage on patient outcomes: a systematic review and meta-analysis. Arch Intern Med 2011;171(6):498-506.

73. Kim HJ. Professor Jinhyeong Kang "Digital healthcare will break the existing system" [Internet]. Seoul, Korea: HITnews; 2021 [cited at 2022 Feb 3]. Available from: http://www.hitnews.co.kr/news/articleView. html?idxno=32291. 